\title{
Influence of Activator on the strength of Ultra Fine Natural Steatite Powder based on Geopolymer Mortar
}

\author{
Premkumar R, Ramesh BabuChokkalingam, M Shanmugasundaram
}

\begin{abstract}
In this study the detailed analysis was made on alkali activated ultra fine natural steatite powder (UFNSP) mortars. The activating alkali was prepared through sodium hydroxide and sodium silicate with different molarities concentration of $\mathrm{NaOH}$. The molarities of $\mathrm{NaOH}$ are various from $8,10,12,14$ and 16. The proportion of sodium hydroxide and sodium silicate proportion are fixed 1:2.5. Further the strength gained was accelerated through polyvinyl alcohol [PVA]. And various water binder ratio of 0.5, 0.6, 0.7, 0.8 and 0.9 with addition of PVA. For workability purpose super plasticizer was used, here Poly carboxylic ether was used as a superplasticizer. These various ratios concentration of alkali activators were tried on compressive strength of polymer mortar and the results were discussed. The watched outcomes demonstrate that, increment in sodium hydroxide content in soluble base fluid expands the strength. Exhibit the outcome was effect of Si/Al proportion on compressive strength of the specimen with various water binder proportions. In general, the study shows that integrating low ratio of Si/Al content in UFNSP with PVA can fetch low binding property on alkali activator UFNSP material.
\end{abstract}

Keywords :Mortar strength, PVA, Si/Al ratio, Steatite Powder.

\section{INTRODUCTION}

Geopolymers have developed as a new development designing materials with the possibility to frame another component of an ecologically maintainable development and building items. These geopolymers have a low greenhouse impression when contrasted with preservationist bond concrete. Alkali activator type and its fixation assume the most significant job in the quality of geopolymers [1]. So as to guarantee practical advancement, specialists all around the globe have concentrated their examination on supplanting and reusing waste materials to supplant normal materials.Dr. K. Sudalaimani and Dr.M.Shanmugasundaram. [2] Determined about the cement setting time and pozzolanic activity and also they did UFNSP replacement of $5 \%, 10 \%$, $15 \%, 20 \%, 25 \%$ with mass of cement and tested using XRD,

Revised Manuscript Received on December 5, 2019

* Correspondence Author

Premkumar $\mathbf{R}^{*}$, School of Environmental and Construction Technology, Department of Civil Engineering, Kalasalingam Academy of Research and Education, Krishnan Koil, Tamil Nadu, India. Email: prem.ce@gmail.com

Ramesh BabuChokkalingam, School of Environmental and Construction Technology, Department of Civil Engineering, Kalasalingam Academy of Research and Education, Krishnan Koil, Tamil Nadu, India. Email: babussr@gmail.com

M Shanmugasundaram, School of Mechanical and Building Sciences, Vellore Institute of Technology, Chennai, Tamil Nadu, India, shanmugaresearch@gmail.com
SEM analysis, also studied micro structural behavior, chemical element distribution. Founded that the dormant period shortened, initial and final setting time reduced. Compressive strength, consistency of binding material for C5, C10, C15 was also studied. It shows denser micro structural bond in $\mathrm{C} 15$ and denser hydration product in $\mathrm{C} 20$ and micro structural similarity in $\mathrm{C} 25$ showed disintegrated micro structure, low density. It is concluded that utilization with cement component not more than $20 \%$. They concluded percentage should not exceed 20\%. De Molcon'sRecuielIndustriel[3] Determined Specific gravity of steatite as 2.60 to 2.66, used more common in Germany and in Cornwall, western parts of France. Mixture of silex, alumine, magnesia, oxide of iron and water gave more durability and it did not affect colours. When it was combined with oil or grease, it goes into creation of larger pieces of balls and when blended with oil it was utilized to clean glass and metallic mirrors. M.Palacios [4] told except naphthalene based product, the product lost fluidity property. A mortar activated with $\mathrm{NaOH}$ act as shrinkage reducing admixtures and decrease surface tension, lowers capillary tension and furthermore diminished shrinkage during vanishing of water. Sodium lignosulphonate and naphthalene reduces compressive strength without improving workability but when naphthalene used with $\mathrm{NaOH}$ not altered formulation but gave rise in mechanical strength [5].

\section{MATERIALS}

\section{A. Steatite Powder (UFNSP)}

Steatite is otherwise called soapstone, which is a kind of transformative shake and has a lot of mineral powder. It is wealthy in magnesium. It is produced by dynamo-thermal metamorphism, which occurs in the zones where tectonic plates are sub ducted. Steatite is the softest material than all other minerals which is rated as one on mohs hardness scale. Chemical properties of steatite powder were $\mathrm{SiO}_{2}-62.67 \%$, $\mathrm{Al}_{2} \mathrm{O}_{3}-0.24 \%, \mathrm{MgO}-33.26 \%, \mathrm{Fe}_{2} \mathrm{O}_{3}-0.30 \%, \mathrm{CaO}-0.20 \%$. There is no fixed hardness for soapstone because the amount of talc varies in it. Steatite is a softest material.

\section{B. Alkaline Solution}

Sodium silicate and sodium hydroxide are used to make alkali activated solution. The soluble base utilized was comprised of a blend of $\mathrm{NaOH}$ and $\mathrm{Na}_{2} \mathrm{SiO}_{3}$ arrangement. A $\mathrm{NaOH}$ solids piece must be liquefied in refined water to make a solution with the required concentration. 
In this investigation, different molarities of sodium hydroxide concentration were used to manufacture various specimens. For instance 400 grams of sodium hydroxide in drop structure is broken down in 1 liter of impartial water to make 10Molarity arrangement. $\mathrm{NaOH}$ and $\mathrm{Na}_{2} \mathrm{SiO}_{3}$ were mixed in the fixed ratio of 1:2.5 [6] and this liquid is used for the preparation of specimens.

\section{Superplasticizer}

In this study has used superplasticizer as Poly carboxylic ether with low dosage of $0.2 \%$ by weight of binding materials. Its allow water reduction up to $40 \%$ which enables good particle dispersion and composed by methoxy poly ethylene glycol co-polymer, grafted with methacrylic acid co-polymer. It grants adsorption on the emphatically charged colloidal particles. This displacement of polymer on particle surface ensures the possibility to exert repulsion forces which disperse the particles of suspension and avoid friction.

\section{Polyvinyl Alcohol (PVA)}

PVA is a manufactured polymer with the equation $\left[\mathrm{CH}_{2} \mathrm{CH}(\mathrm{OH})\right]_{\mathrm{n}}$. It is used as an emulsion polymerization aid, and it makes dispersion of polyvinyl acetate, as protective colloid.It has a softening purpose of $230^{\circ} \mathrm{C}$ for completely hydrolyzed and for in part hydrolyzed evaluation it is $180-190^{\circ} \mathrm{C}$. Poisson's proportion is somewhere in the range of 0.42 and 0.48 .

\section{E. Fine Aggregate}

Aggregate are utilized for financial condition. What's more, it is utilized as filler and it don't respond with cement mortal. The advancement of hard bond quality between aggregate particles and cement glue relies superficially surface, surface harshness and porosity of aggregate. Using fine aggregate was conforming to Zone II of IS 383-1970 having specific gravity 2.63 and fineness modulus 3.10 . Water absorption and bulk density were $0.85 \%$ and $1.25 \mathrm{~kg} / \mathrm{m}^{3}$

\section{METHODS AND CASTING}

\section{A. Mix Proportion}

Sums oftwenty blends were made to examination the impact of different centralizations of $\mathrm{NaOH}$ solids with various activator binder proportions on compressive strength. The details of these mixtures are showing in table I. The aggregate binder mixes kept constant ratio of $1: 3$ for all mix proportion. The mortar paste mix proportion of components was considered based on the absolute volume method. In this test work, geopolymer mortar was set up with five unique molarities of sodium hydroxide arrangements i.e; $8 \mathrm{M}, 10 \mathrm{M}$, $12 \mathrm{M}, 14 \mathrm{M}$ and $16 \mathrm{M}$. The heaviness of atomic sodium hydroxide is $40 \mathrm{gm}$. sodium hydroxide is set up by dissolving pellets in water. The mass of $\mathrm{NaOH}$ differed relying upon the centralization of arrangement. Proportion of sodium hydroxide to sodium silicate utilized in this ratio is 2.5[7]. Table II shows required solid content was measured with corresponding molarities [8]

Table- I: Mix Proportion

\begin{tabular}{|c|c|c|c|c|c|c|c|c|}
\hline $\mathbf{S . N o}$ & $\mathbf{N a O H}$ & $\begin{array}{c}\mathbf{N a O H} \\
\mathbf{g} / \mathbf{l}\end{array}$ & $\begin{array}{c}\mathbf{N a} \mathbf{2}_{\mathbf{s i o}} \mathbf{3} \\
\mathbf{g} \mathbf{l}\end{array}$ & $\begin{array}{c}\mathbf{U F N S P} \\
\mathbf{k g} / \mathbf{m}^{\mathbf{3}}\end{array}$ & $\begin{array}{c}\mathbf{S a n d} \\
\mathbf{k g} / \mathbf{m}^{\mathbf{3}}\end{array}$ & $\begin{array}{c}\mathbf{N a o h} / \\
\mathbf{B i n d i n g}\end{array}$ & $\mathbf{W / B}$ Ratio & PVA \\
\hline 1 & 320 & 262 & 655 & 750 & 2250 & 0.35 & 0.5 & $1 \%$ \\
\hline 2 & 400 & 312 & 780 & 750 & 2250 & 0.42 & 0.5 & $1 \%$ \\
\hline 3 & 480 & 362 & 905 & 750 & 2250 & 0.48 & 0.5 & $1 \%$ \\
\hline 4 & 560 & 404 & 1010 & 750 & 2250 & 0.54 & 0.5 & $1 \%$ \\
\hline 5 & 640 & 444 & 1110 & 750 & 2250 & 0.59 & 0.5 & $1 \%$ \\
\hline 6 & 320 & 262 & 655 & 750 & 2250 & 0.35 & 0.6 & $1 \%$ \\
\hline 7 & 400 & 312 & 780 & 750 & 2250 & 0.42 & 0.6 & $1 \%$ \\
\hline 8 & 480 & 362 & 905 & 750 & 2250 & 0.48 & 0.6 & $1 \%$ \\
\hline 9 & 560 & 404 & 1010 & 750 & 2250 & 0.54 & 0.6 & $1 \%$ \\
\hline 10 & 640 & 444 & 1110 & 750 & 2250 & 0.59 & 0.6 & $1 \%$ \\
\hline 11 & 320 & 262 & 655 & 750 & 2250 & 0.35 & 0.7 & $1 \%$ \\
\hline 12 & 400 & 312 & 780 & 750 & 2250 & 0.42 & 0.7 & $1 \%$ \\
\hline 13 & 480 & 362 & 905 & 750 & 2250 & 0.48 & 0.7 & $1 \%$ \\
\hline 14 & 560 & 404 & 1010 & 750 & 2250 & 0.54 & 0.7 & $1 \%$ \\
\hline 15 & 640 & 444 & 1110 & 750 & 2250 & 0.59 & 0.7 & $1 \%$ \\
\hline 16 & 320 & 262 & 655 & 750 & 2250 & 0.35 & 0.8 & $1 \%$ \\
\hline 17 & 400 & 312 & 780 & 750 & 2250 & 0.42 & 0.8 & $1 \%$ \\
\hline 18 & 480 & 362 & 905 & 750 & 2250 & 0.48 & 0.8 & $1 \%$ \\
\hline 19 & 560 & 404 & 1010 & 750 & 2250 & 0.54 & 0.8 & $1 \%$ \\
\hline 20 & 640 & 444 & 1110 & 750 & 2250 & 0.59 & 0.8 & $1 \%$ \\
\hline
\end{tabular}


Table- II: Section Properties of Castellated Beam

\begin{tabular}{|c|c|c|}
\hline S.No & Molarities & $\begin{array}{c}\text { Weight Solid in } \\
\text { NaOH grams }\end{array}$ \\
\hline 1 & 8 & 262 \\
\hline 2 & 10 & 312 \\
\hline 3 & 12 & 362 \\
\hline 4 & 14 & 404 \\
\hline 5 & 16 & 444 \\
\hline
\end{tabular}

\section{B. Casting and Curing}

The mixing of UFNSP with fine aggregate was dry mixed in the one to two minutes then PVA is added and mixed for one minute. Then super plasticizer and alkaline solution were added right away to the dry mix. The mixing methodology continued with the objective that absolutely homogeneous glue can be got. At that point, the acquired geopolymer mortar were filled the cube moulds $100 \mathrm{~mm} \times 100 \mathrm{~mm} \times$ $100 \mathrm{~mm}$ before being totally inflexible, and after $24 \mathrm{~h}$ they were expelled from the form and relieved at a temperature $70^{\circ} \mathrm{c}$ in oven for a period of 48 hours. After the specimens were kept in room temperature and measured compressive strength after 28 days

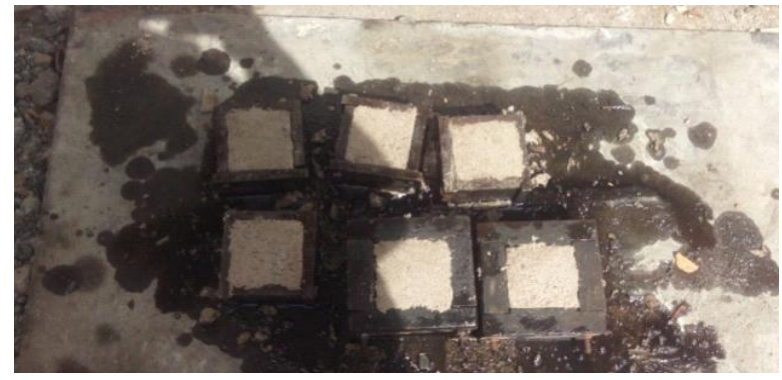

Fig. 1.Casting of Geopolymer Mortar

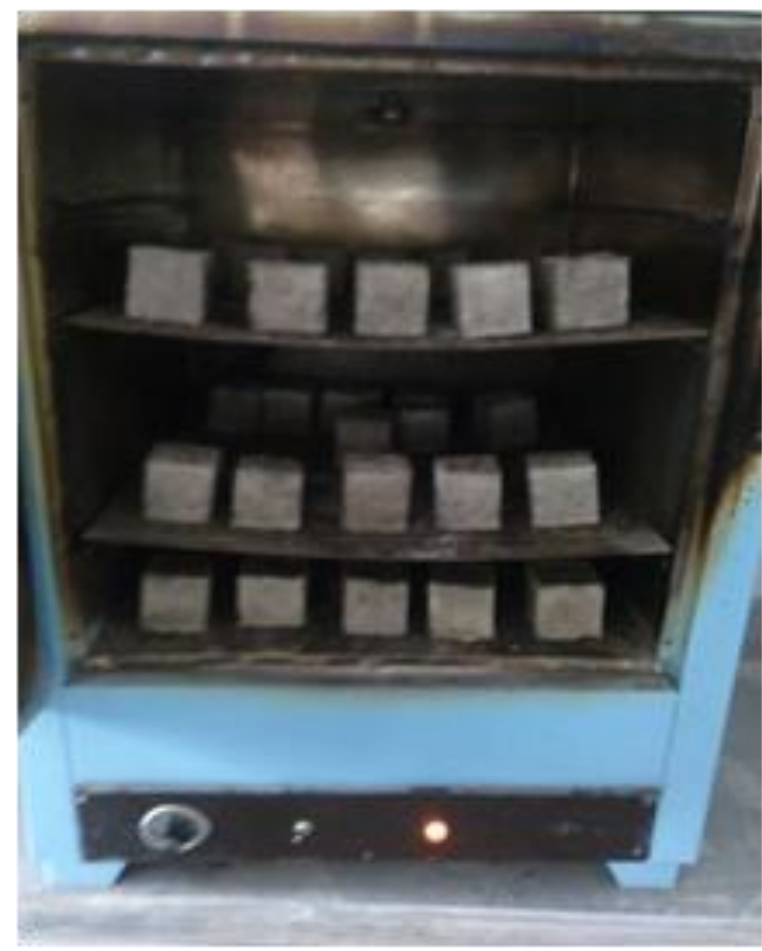

Fig. 2.Curing of Mortar Cube

\section{RESULT AND DISCUSSION}

\section{A. Compressive Strength}

The estimations of normal compressive strength and standard deviation for mortar cube shapes in proportion 1:3 for various molarities were appeared in figures 3 to 7 . The compressive strength of geopolymer mortar is usually viewed as its most significant trademark. The test results of twenty mix proportion were presented in the figures 3 to 7 . All the mix proportion results were compared with known value of $43 \mathrm{MPa}$ in $48 \mathrm{~h}$ (Davidovits). The M8 mix proportion with W/B ratio 0.7 achieves only $51 \%$ of the total required strength geopolymer mortar cube and addition of W/B ratio decline the strength. The M10 specimen has an average compressive strength of $24.84 \mathrm{MPa}$ which is $56 \%$ of strength to be attainment of objective value on $\mathrm{W} / \mathrm{B}$ ratio 0.7 . But the strength of M10 value is greater than M8. As can be found from investigation the effect of W/B ratio increase 0.5 to 0.9 , initially increase the compressive strength of the mortar further decline the strength and workability of specimens. The M12 shows the average compressive strength of 27.37MPa and M14 shows average compressive strength of $32.7 \mathrm{MPa}$ at the water binder ratio 0.7 . The M14 has almost achieve the nominal strength of PPC cement mortar was attained. The compressive strength of M16 was periphery increase with respect to $\mathrm{W} / \mathrm{B}$ ratio.

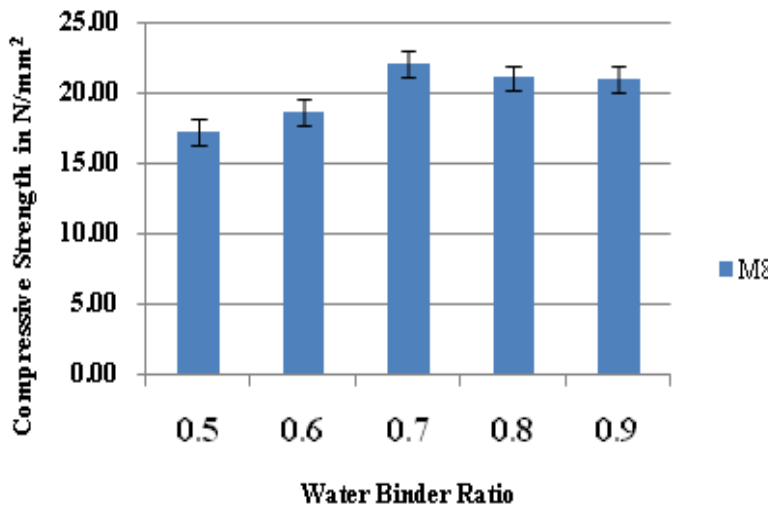

Fig. 3.Effect of Water Binder Ration on Compressive Strength of M8

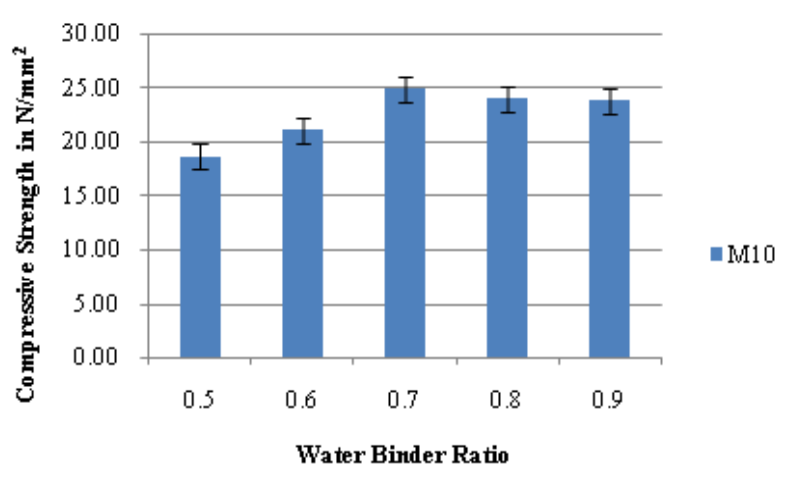

Fig. 4.Effect of Water Binder Ration on Compressive Strength of M10

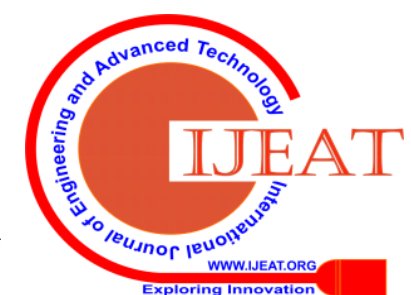




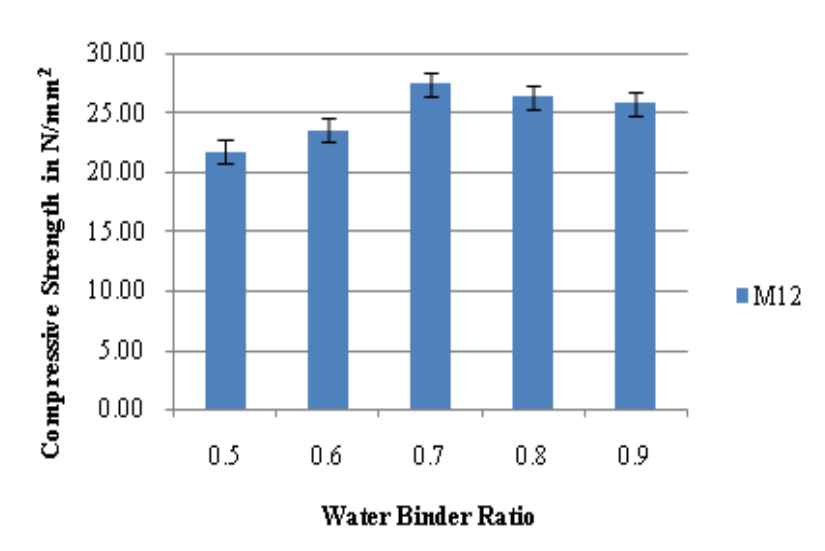

Fig. 5.Effect of Water Binder Ration on Compressive Strength of M12

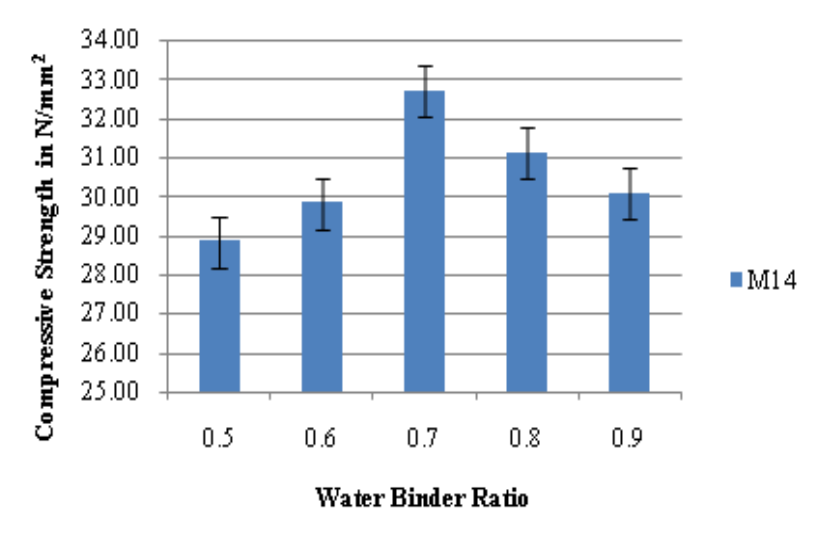

Fig. 6.Effect of Water Binder Ration on Compressive Strength of M14

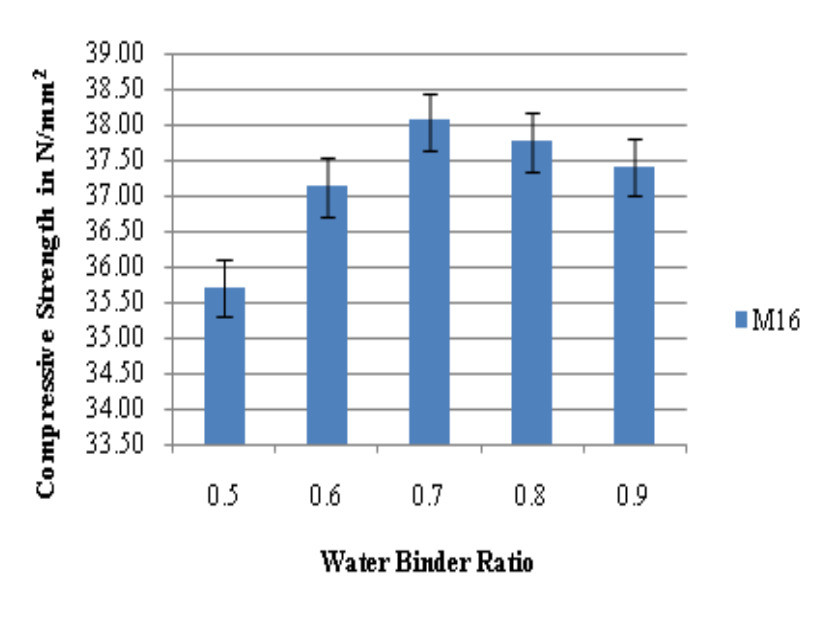

Fig. 7.Effect of Water Binder Ration on Compressive Strength of M16

\section{B. Effect of $\mathrm{NaOH}$ Binder Ratio}

Mix proportions of geopolymer mortars (relate to 0.35 , $0.42,0.48,0.54$ and 0.59 individually) were set up to investigation the impact of water to binder proportion on the compressive quality of the geopolymer mortar. Figure 8 outlines the impact of water to strong proportion on the compressive quality. As it was unsurprising developing the water to strong proportion diminished the 28 days compressive strength; however, as it can be observed thee ratios of $\mathrm{NaOH}$ to binder and water binder ration another way influence the compressive strength of geopolymer mortars. As preserve be establish from Figures 6, the effect of water binder ratio is unbalanced, however, the compressive strength is growing with the increment of $\mathrm{NaOH}$ binder ratio. As shown in figure 8 compressive strength of the geopolymer mortar increases with solid content of sodium hydroxide to binder ratio increasing from 0.35 to 0.59 , whereas there is an decreasing tendency in compressive strength with water / binder ratio rising from 0.5 to 0.9 [9]. At steady activator to binder ratio and lime extent, expanding solid to binder proportion means expanding molarity of activator, and different specialists found that the molarity of basic arrangement affects the quality of geopolymer binder [10],[11].

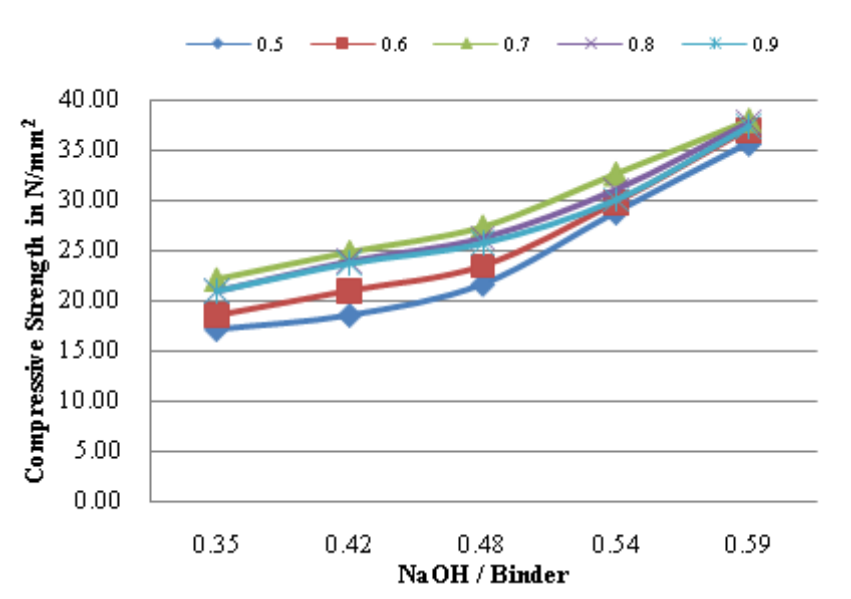

Fig. 8.Effect of $\mathrm{NaOH} /$ Binder ratio with Water Binder Ratio

\section{CONCLUSION}

- Higher the $\mathrm{NaOH}$ fixation higher the strength was observed, which demonstrates that no delaying alkaline is formed even in 16 Molarity.

- With the water binder proportion expanding from 0.5 to 0.9 , compressive strength of the mortar builds first, and after that diminishes. The water / binder ratio also affects the compressive strength of geopolymer mortars.

- It is comprehended that higher water binder proportion will prompt lower compressive strength because of the vanishing of free water atoms as affirmed result investigation.

- It very well may be deduced that the more $\mathrm{Si} / \mathrm{Al}$ proportion geopolymer mixers profit by, the higher strength can be normal.

- From all of the results it will in common be considered that the alkaline solution nearby steatite powder can go about as binder, the objective strength improvement in this alkali activated steatite based binder couldn't be accomplished by expanding $\mathrm{NaOH}$ solid substance and water binder proportion of geopolymer mortar.

Published By: 419 Blue Eyes Intelligence Engineering \& Sciences Publication 


\section{REFERENCES}

1. Connie Ng, U. Johnson Alengaram , Leong Sing Wong, Kim Hung M, MohdZaminJumaat, and S. Ramesh, "A review on microstructural study and compressive strength of geopolymer mortar, paste and concrete", construction and Building Materials, vol.186, pp. 550-576, 2018.

2. Sudalaimani. K and Shanmugasundaram. M, "Influence of Ultrafine Natural Steatite Powder on setting time and Strength Development of Cement", Advances in Materials Science and Engineering, vol. 2014, Article ID 532746, 2014. Available from: http://dx.doi.org/10.1155/2014/532746

3. De Molcon'sRecuielIndustriel, "on the uses of steatite; and particularly in the lubrication of ma-chinery to reduce friction" Journal of the Franklin Institute, 5 (1830)

4. M.Palacios, F.Puertas, "Effect of Super Plasticizer and Shrinkage Reducing Admixtures on Alkali Activated Slag Pastes and Mortars",Cement and Concrete Research, vol. 35(7), pp1358-1367, 2004, DOI: 10.1016/j.cemconres.2004.10.014

5. Dr. S. G. Shah Parth, D. Parikh Harshvardhan, S. Mehta Vishal and R. Trivedi, "A Study on Effect of Curing Condition \& Molarity Concentration on Geo-polymer Concrete", Indian Journal Of Applied Research, vol.5(1),pp. 60-63, 2015

6. Shanmugasundaram M, Premkumar R, Abinaya, Arunya KG, Gowsalya $\mathrm{M}$ andMalathy $\mathrm{M}$, "A new cement free binding material based on steatite powder activated through alkaline solution" Master Builder, vol 18(3),pp. $60-64,2016$

7. R Premkumar, Ramesh BabuChokkalingam and M Shanmugasundaram, "Durability Performance of Fly Ash and Steatite Powder Based Geopolymer Concrete", IOP Conference Series: Materials Science and Engineering, vol. 561, 012055, 2019, Available from: https://doi.org/10.1088/1757-899X/561/1/012055

8. RobinaKouserTabassum, AnkushKhadwal, "Effect of Sodium Hydroxide Concentration on Various Properties of Geopolymer Concrete", International Journal of Engineering and Technical Research (IJETR), vol. 3(10), pp.454-4698, 2015

9. AndiArham Adam, BayuRahmatRamadhan, and ShyamaMaricar, "The Effects of Water to Solid Ratio, Activator to Binder Ratio, and Lime Proportion on the Compressive Strength of Ambient-Cured Geopolymer Concrete ",Journal of the Civil Engineering Forum, vol.5(2), pp.161-168, 2019, Available from:https://doi.org/10.22146/jcef.43878 .

10. Keun-Hyeok Yang, Hey-Zoo Hwang, and Seol Lee, "Effects of Water-Binder Ratio and Fine Aggregate-Total Aggregate Ratio on the Properties of Hwangtoh-Based Alkali-Activated Concrete “,J. Mater. Civ. Eng, vol.22(9), pp.887-896, 2010, Available from:DOI: 10.1061/ ASCE MT.1943-5533.0000091.

11. Zhang $\mathrm{P}$, Zheng Y, Wang K, Zhang J, A review on properties of fresh and hardened geopolymer mortar, Composites Part B (2018), Available from: Doi: 10.1016/j.compositesb.2018.06.031

\section{AUTHORS PROFILE}

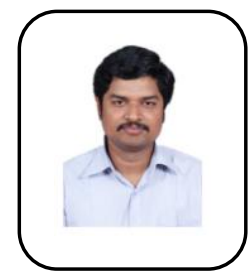

R.Premkumar had completed B.E degree in Civil Engineering and M.E degree in Structural Engineering from Anna University, Chennai, Tamil Nadu in 2008 and 2012 respectively. He is currently working as Assistant Professor in the department of Civil Engineering at Kalasalingam Academy of Research and Education. He has 2 year of industrial experience and 7 years' experience in academics and consultancy. His current research interests are Geopolymer Concrete and Earthquake resistance structures.

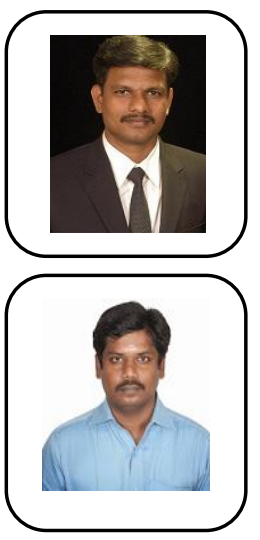

Ramesh Babu Chokkalingam completed his Ph.D. from IIT Chennai. He has more than ten years of experience in teaching and research. His areas of research includes pervious concrete, geopolymer concrete, and high volume flyash concrete.

DrM.Shanmugasundaram: He had completed his B.E degree in Civil Engineering from RCET Madurai, M.E in Structural Engineering, TCE Madurai. He completed his Ph.D in 2014 under the esteemed guidance ofDr. K.Sudalaimani, Professor, TCE, Madurai. He has 30+ international research publications to his credits. He had filed three patents. He has 3 years of industrial experience and 10 years of teaching experience. His recent research interests include, sustainable materials and polymer concrete. 